Polymer Degradation and Stability

August 2017, Volume 142, Pages 169-177

http://dx.doi.org/10.1016/i.polymdegradstab.2017.06.005

http://archimer.ifremer.fr/doc/00388/49904/

(C) 2017 Elsevier Ltd. All rights reserved.

\title{
Kinetic analysis of polydicyclopentadiene oxidation
}

\author{
Defauchy Virginie ${ }^{1}$, Le Gac Pierre-Yves ${ }^{2}$, Guinault Alain ${ }^{1}$, Verdu Jacques ${ }^{1}$, Recher Gilles ${ }^{3}$, \\ Drozdzak Renata ${ }^{3}$, Richaud Emmanuel ${ }^{1, *}$
}

${ }^{1}$ Laboratoire PIMM, Ensam, CNRS, Cnam, 151 boulevard de l'Hôpital, 75013 Paris, France

2 IFREMER Centre de Bretagne, Marine Structures Laboratory, BP70, 29280 Plouzane, France

${ }^{3}$ TELENE SAS, 2 rue Marie Curie, 59910 Bondues, France

* Corresponding author : Emmanuel Richaud, email address : emmanuel.richaud@ensam.eu

\begin{abstract}
:
The in situ thermal oxidation of thin unstabilized polydicyclopentadiene was studied by TGA to monitor mass gain, and DSC to characterize hydroperoxides concentration. Results were discussed using kinetic analysis, which allowed the estimation of activation energies for key reactions of the oxidation process. Activation energy for termination was shown to be higher than in hydrocarbon liquids, which was discussed from the theory of diffusion controlled reactions, and a possible link with local motions associated with sub-glassy transition. Activation energy of thermal decomposition of hydroperoxides was found lower than for model hydroperoxides, suggesting an accelerating effect of organometallic catalysts. Despite those two results that indicate a poor thermal stability of thin pDCPD films, measurements of oxygen diffusivity at several temperatures show that oxidation remains confined in a relatively thin surface layer which would allow the pDCPD properties to be preserved.
\end{abstract}

Keywords : Polydicyclopentadiene, Thermal oxidation, Segmental mobility, Catalysis, Diffusion limited oxidation 
INTRODUCTION

In the case of a single bimolecular radical reaction: $A^{\circ}+B^{\circ} \rightarrow$ inactive species, the rate of radical depletion depends on: (1) their initial concentration, i.e. the average distance between the closest reactant molecules; (2) the rate at which they move into the reactive medium (expressed in terms of diffusion coefficient); (3) geometric and thermochemical factors determining the probability to react. These later can be expressed for instance as the capture radius in the Waite's theory $\left[\begin{array}{l}1 \\ ,\end{array}\right]$.

The domain of high reactant concentrations and high reactant mobility corresponds to the domain of classical chemical kinetics. Bimolecular rate constants only depend on geometric and thermochemical factors but are independent of time and reactant concentrations. When the concentration or the mobility of reactants decreases, the system reaches a limit beyond which the rate constant begins to fall because the time between encounters becomes a non-negligible fraction of the whole reaction time. Here, it is better to consider that the reactivity is ruled by an apparent rate constant depending in part on the diffusivity of macroradicals.

Polydicyclopentadiene ( $\mathrm{PDCPD}$ ) is from this point of view quite attracting. It is obtained by metathesis of dicyclopentadiene. This polymerization mechanism (awarded by Nobel Prize in 2005 $\left.\left[\begin{array}{l}3 \\ ,\end{array}\right]\right)$ allows the production of a bulky material from a low viscosity reactive mixture in a short processing time (ca $1 \mathrm{~min}$ ) without external heating. Beside those practical advantages for designing thermosets, PDCPD is interesting from the "degradation" point of view because of its high level of double bonds together with a glassy behavior (its $\mathrm{T}_{\mathrm{g}}$ is close to $160^{\circ} \mathrm{C}$ ). In other words, it offers the double interest:

- to investigate the possible "tradeoff" between its easy polymerization and its oxidative stability, - to study theories on diffusion controlled reactions.

In a recent paper $\left[{ }^{5}\right]$, the rate constants of $\mathrm{PDCPD}$ oxidation reactions were estimated from the simulation of carbonyls and hydroperoxides curves and linked with the possible origins of PDCPD oxidizability. It was shown that both high initiation rate constants and low termination rate constants were needed to simulate the kinetic curves for carbonyls and hydroperoxides under air. Our paper left several questions which still are unanswered among which:

- how can we determine the kinetic parameters using a different approach than their adjustment from experimental curves performed in $\left[^{5}\right]$ in order to confirm the previous findings?

- what happens in the case of thick samples? 
- what are the consequences of oxidizing at glassy state on termination reactions, i.e. which reactions $\left(\mathrm{P}^{\circ}+\mathrm{P}^{\circ} \rightarrow \ldots, \mathrm{POO}^{\circ}+\mathrm{P}^{\circ} \rightarrow \ldots, \mathrm{POO}^{\circ}+\mathrm{POO}^{\circ} \rightarrow \ldots\right)$ are impacted? Which mechanisms rule the macromolecular mobility, and what is the role of this later in degradation mechanisms and kinetics? This last question was scarcely addressed in existing papers (see for example $\left[{ }^{6},{ }^{7}\right]$ ) and remains for us open in the field of polymer degradation.

We try here to answer those questions by investigating the PDCPD degradation kinetics in the temperature range $\left[T_{g}-100^{\circ} \mathrm{C} ; T_{g}\right]$. Given the relative fastness of degradation, we have chosen to monitor ageing only by in situ techniques: mass uptake by TGA, and quantification of peroxides using DSC (with direct oxidation of the polymer in DSC cell). Those analyses will be completed with oxygen permeability measurements to understand the control of oxidation by oxygen diffusion. Comparisons will often be done with polybutadiene which has a comparable double bonds concentration but being aged and used in its rubbery state. Last, particular attention will be addressed to the existence of Diffusion Limited Oxidation (DLO) $\left[{ }^{8}\right]$ so as to extract reliable kinetic parameters (i.e. only when samples are not subjecyed to DLO effects). 


\section{EXPERIMENTAL}

\section{Material}

Material from $5 \mathrm{~cm}$ stabilized pDCPD plate was cut in 5-100 $\mu \mathrm{m}$ thin films using a Reichert-Jung microtome. The films were purified by refluxing in $\mathrm{CH}_{2} \mathrm{Cl}_{2}$ overnight and then stored in fridge prior to exposure. As received $175 \mu \mathrm{m}$ stabilized films provided by the supplier were used for permeability measurements.

\section{Ageing and characterization}

\subsection{ThermoGravimetric Analysis (TGA)}

Isothermal gravimetric measurements were monitored using a TGA Q50 (TA Instruments) driven by Q Series Explorer. About $0.1 \mathrm{mg}$ samples were placed in a Platinum pan which was heated under nitrogen till to the measurement temperature (from $105^{\circ} \mathrm{C}$ to $150^{\circ} \mathrm{C}$ ) at which cell atmosphere was switched to nitrogen-oxygen mixtures with oxygen ratio from 0\% to 100\% (using a GasMix device). Results were analyzed using TA Analysis software.

\subsection{In situ hydroperoxides titration by Differential Scanning Calorimetry (DSC)}

Samples were directly oxidized in DSC cell so as to quantify peroxides using the following procedure:

- heating to the ageing temperature under nitrogen $\left(10^{\circ} \mathrm{C} \mathrm{min}^{-1}\right)$

- isothermal ageing under 1 bar of oxygen at temperatures ranging from 50 to $120^{\circ} \mathrm{C}$

- cooling down to room temperature under nitrogen $\left(10^{\circ} \mathrm{C} \mathrm{min}^{-1}\right)$

- heating to $280^{\circ} \mathrm{C}$ under nitrogen $\left(10^{\circ} \mathrm{C} \mathrm{min}^{-1}\right)$

Analyses were done using a DSC Q10 apparatus (TA Instruments) with Aluminum pans (the lid was manually drilled to ensure the access of oxygen) under $50 \mathrm{ml} \mathrm{min}^{-1}$ flow of oxygen or nitrogen. Only one single PDCPD foil (about $0.2 \mathrm{mg}$ ) was used to avoid complications due to Diffusion Limited Oxidation. Results were interpreted using TA Analysis software. 


\subsection{Permeability}

As received $175 \mu \mathrm{m}$ thin pDCPD films maintained in a mask (with an accessible surface $\mathrm{ca} 5 \mathrm{~cm}^{2}$ ) were placed between the two compartments of a Systech 8001 permeameter. The cell and the sample were completely purged during one week in order to avoid oxygen diffusivity underestimation due to residual oxygen present in the polymer bulk. Purge was performed at room temperature to avoid in situ oxidation. Pure oxygen (99.9\%) was then introduced into the upper half of the chamber while an oxygen-free carrier gas flowed through the lower half. A coulometric sensor monitored the oxygen flow through the sample induced by oxygen pressure difference.

The onset time (or time lag) $\tau$ expresses the time which is necessary for oxygen to go across the sample. The analytical solution of Fick's law in a case of an infinite plate of thickness $L$ with penetrant at $a C_{s}$ concentration on one edge and 0 at the other allows to determine the diffusion coefficient of oxygen by the equation $\left[{ }^{9}{ }^{10}\right]$ :

$$
\tau=\mathrm{L}^{2} / 6 \mathrm{D}_{\mathrm{O} 2}
$$

Measurements were performed at $23,35,40$ and $50^{\circ} \mathrm{C}$. 
RESULTS

1. ThermoGravimetric results

Gravimetry is a simple technique for characterizing polymer oxidation $\left[{ }^{11}, 12,13,14\right]$ and measure the increase in mass induced by the grafting of oxygen on the polymer skeleton. This sensitive and in situ technique thus allows to following a simple and reliable manner the oxidation kinetics.

\subsection{Effect of sample thickness}

Samples with thicknesses ranging from 5 to $150 \mu \mathrm{m}$ were aged at 120 and $150^{\circ} \mathrm{C}$ under 1 bar $\mathrm{O}_{2}$ so as to determine the maximal thickness below which oxidation is not controlled by oxygen diffusion. TGA curves are presented in Figure $1 \mathrm{a}$. At $150^{\circ} \mathrm{C}$, the induction period duration is negligible (less than 5 $\mathrm{min}$ ) and the rate of mass uptake (linked to the oxidation rate $r_{0 x}$ as shown in "APPENDIX") reaches rapidly its maximal value $\left(r_{m}\right)$. The maximal rate seems almost constant for samples having a thickness lower than ca $20 \mu \mathrm{m}$ (Figure 1b) which corresponds here to twice the Thickness of Oxidized Layer (TOL) $\left[{ }^{11-13}\right]$. In the following, TOL will hence be assumed higher than $10 \mu \mathrm{m}$ for temperatures lower than $150^{\circ} \mathrm{C}$, since the temperature dependence for oxidation rate is higher than for oxygen diffusion (as discussed later). This is consistent with the value ca $15 \mu \mathrm{m}$ observed at $120^{\circ} \mathrm{C}$ (Figure 1b). 


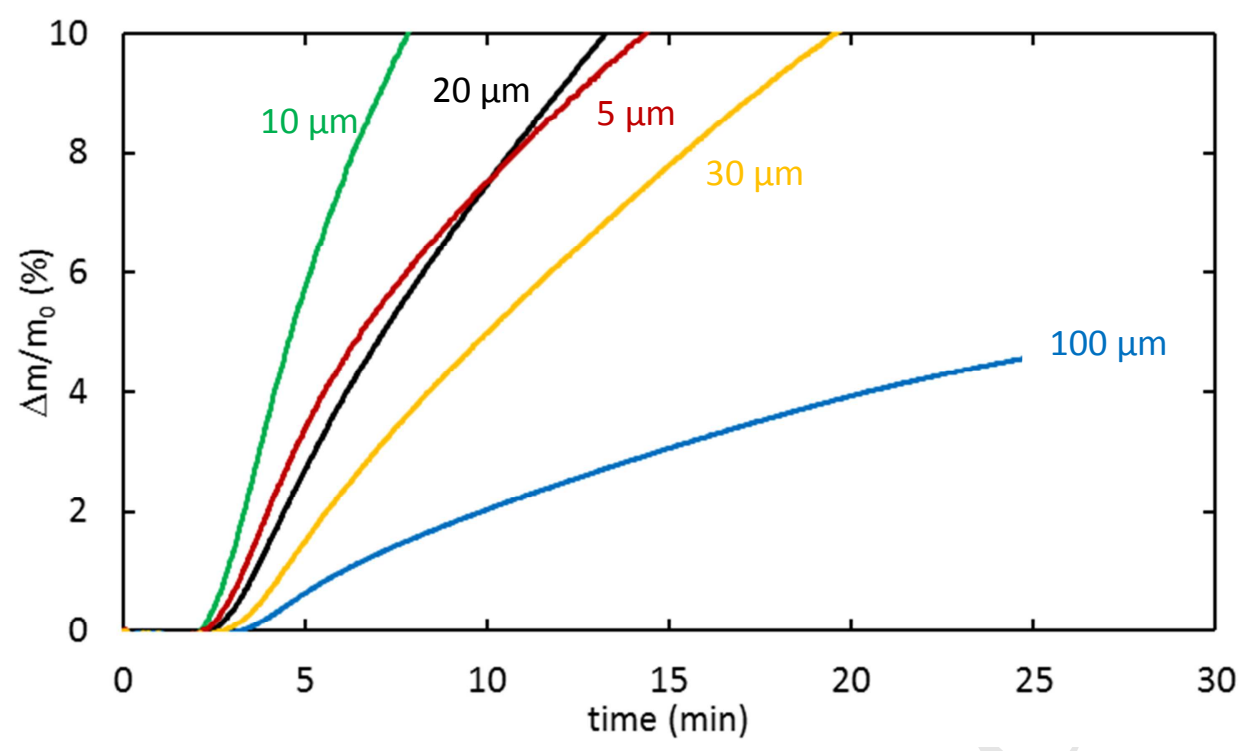

(a)

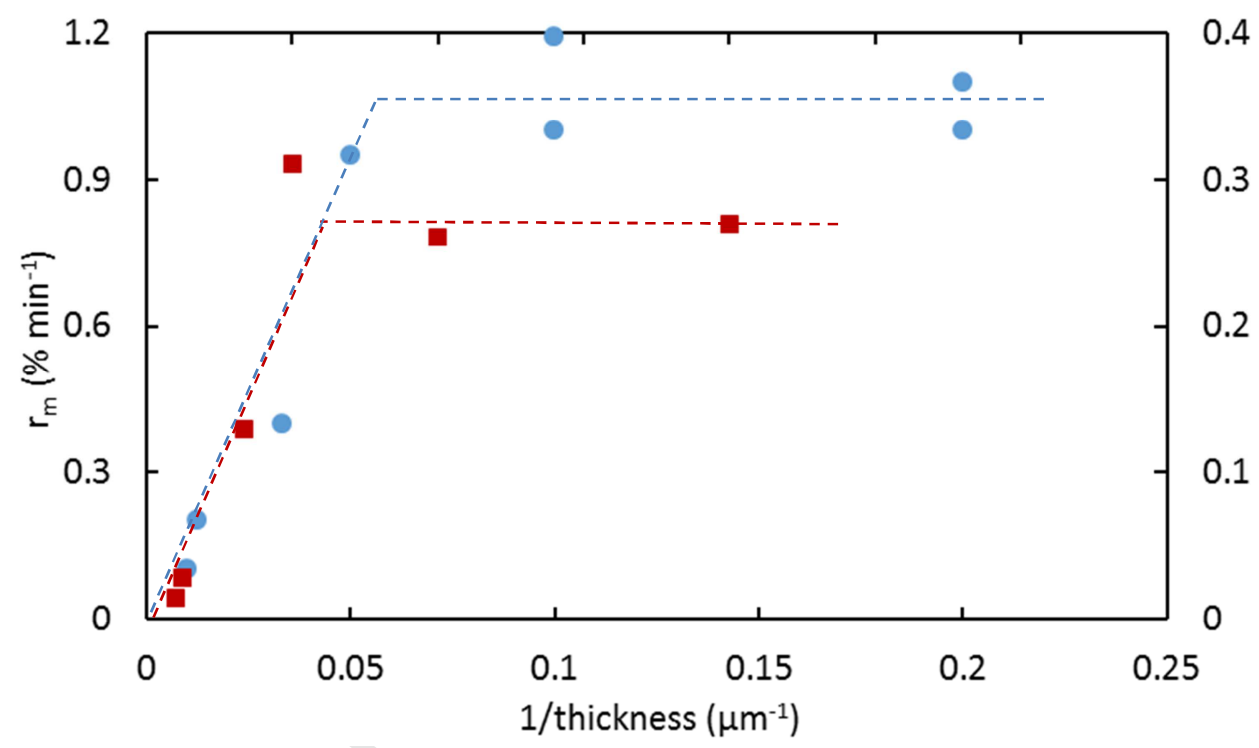

(b)

Figure 1. Gravimetric curves (a) and maximal oxidation rate $\left(r_{m}\right)$ versus reciprocal thickness (b) for unstabilized pDCPD films aged at $150^{\circ} \mathrm{C}\left(\bullet\right.$, left axis) and $120^{\circ} \mathrm{C}\left(\boldsymbol{\square}\right.$, right axis) under 1 bar $\mathrm{O}_{2}(\mathrm{NB}$ : dashed lines guide the eyes).

\subsection{Temperature effect}

In order to consider the temperature effect on oxidation rate of pDCPD, mass uptake for $20 \mu \mathrm{m}$ thin samples were recorded at several temperatures ranging from 105 to $150^{\circ} \mathrm{C}$ under 1 bar of $\mathrm{O}_{2}$. TGA curves (Figure 2) are characterized by:

- an induction period, the duration of which decreases when increasing temperature. 
- an auto-acceleration till to a maximal oxidation rate value which increases with temperature.

- a plateau ca $25 \%$ which is in a first approach independent of the ageing temperature.

- a small mass loss can be observed. It seems to be masked by the oxidation induced weight increase at $150^{\circ} \mathrm{C}$. In the absence of definitive explanation, the origin of this weight loss will not be discussed here. However, the results presented later in Fig. 4 under nitrogen suggest the existence of a minor thermolysis process.

One of the most striking features of the TGA curves is the existence of a plateau. The situation is quite different, for example, with PP $\left[{ }^{14}\right]$ and thermosets $\left[{ }^{12,13}\right]$. Apart from a coincidence, the most reasonable explanation is for us the absence of volatile compounds evolved during the oxidation process. This seems very favorable to durability since volatile loss is associated to cracks initiation.

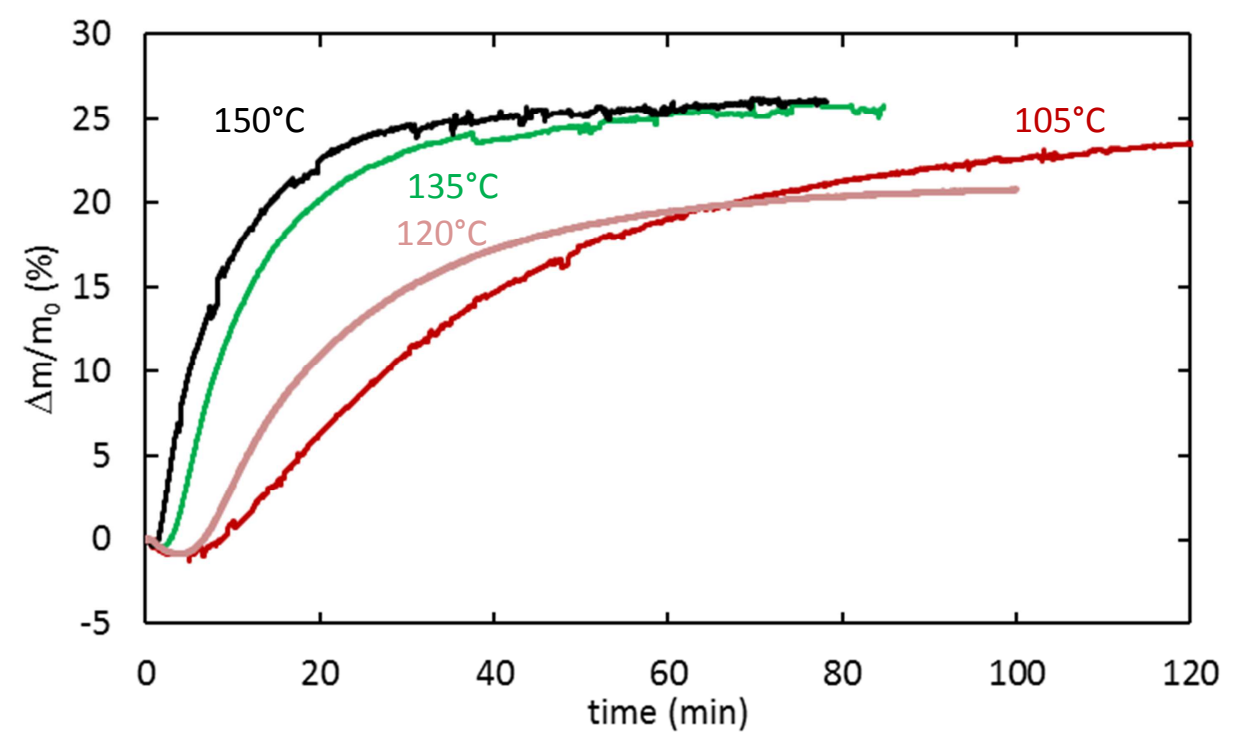

Figure 2. TGA curves of unstabilized $20 \mu \mathrm{m}$ thin PDPCD films at several temperatures under 1 bar of $\mathrm{O}_{2}$.

The maximal rates for mass increase (linked to oxygen absorption) were determined and plotted in an Arrhenius diagram (Figure 3). The apparent activation energy is ca $45 \mathrm{~kJ} \mathrm{~mol}^{-1}$. This is remarkably lower than those of other polymers (as discussed later) whereas mass uptake value at the plateau has a slightly negative activation energy (between 0 and $-5 \mathrm{~kJ} \mathrm{~mol}^{-1}$ ). 


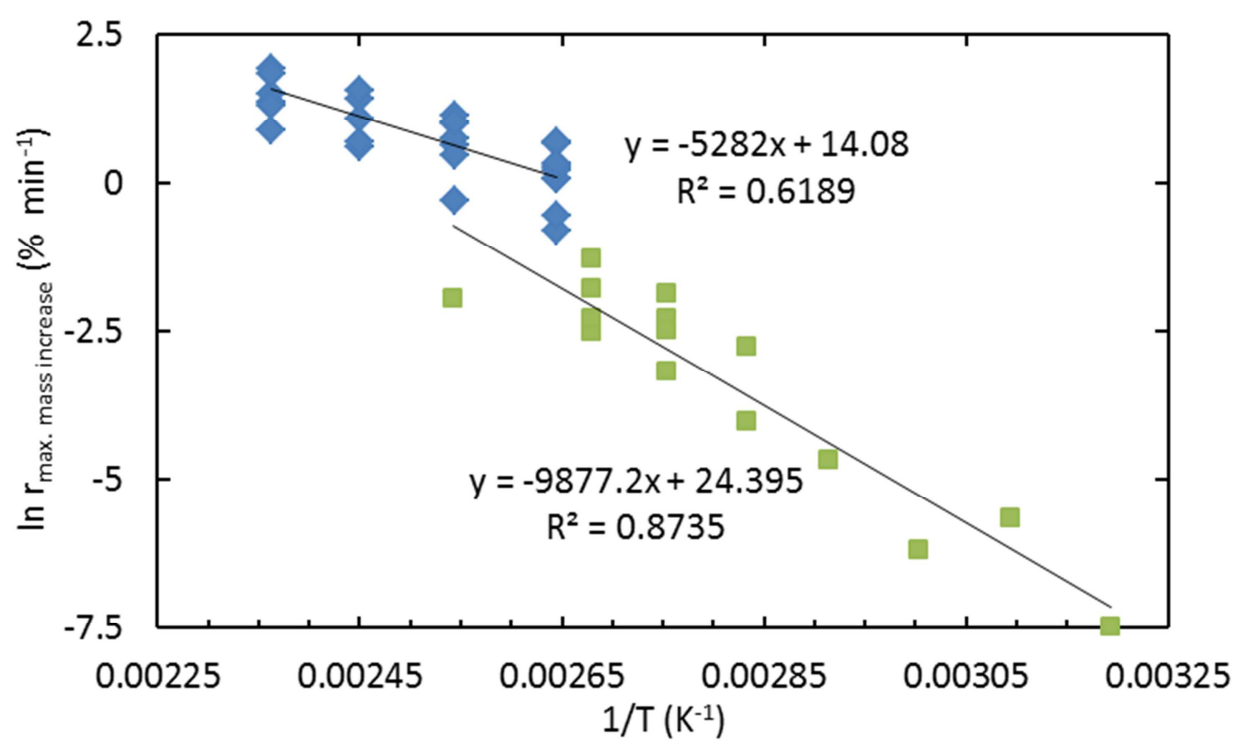

Figure 3. Arrhenius diagram of maximal rate of mass increase derived from TGA curves under 1 bar $\mathrm{O}_{2}$ for $\operatorname{pDCPD}\left(\diamond\right.$, this work) and butadiene rubber $\left(\boldsymbol{\square},\left[{ }^{11}\right]\right)$.

\subsection{Effect of oxygen partial pressure}

Let us recall that the occurrence of termination reactions involving $\mathrm{P}^{\circ}$ decreases when increasing oxygen pressure $\left[{ }^{15}\right]$. An increase in oxygen pressure i.e. in oxygen concentration in the polymer actually favors the reaction between $\mathrm{P}^{\circ}$ and $\mathrm{O}_{2}$ and thus the decrease in $\mathrm{P}^{\circ}$ concentration. Under high oxygen pressure (typically $2.0 \mathrm{MPa}$ of $\mathrm{O}_{2}$ in polychloroprene $\left[{ }^{15}\right]$ or polypropylene $\left[{ }^{16}\right]$ ), the main termination event is thus "POO $+\mathrm{POO}^{\circ} \rightarrow$ inactive products". Inversely, under ambient atmosphere, the " $\mathrm{P}^{\circ}+\mathrm{P}^{\circ} \rightarrow$ inactive products" and " $\mathrm{P}^{\circ}+\mathrm{POO}^{\circ} \rightarrow$ inactive products" reactions will predominate.

The nature of terminations in PDCPD oxidation was investigated by TGA tests performed at $120^{\circ} \mathrm{C}$ under oxygen pressures from 0.05 to 1 bar (Figure 4). Results call for the following comments:

- Under $\sim 5-10 \%$ of $\mathrm{O}_{2}$, no gain in mass is observed. It suggests that an efficient termination process occurs for those ageing conditions. The " $\mathrm{P}^{\circ}+\mathrm{P}^{\circ} \rightarrow$ inactive products" termination would not be controlled by macromolecular mobility possibly because of the radical migration process $\mathrm{P}^{\circ}+\mathrm{RH} \rightarrow$ $\mathrm{PH}+\mathrm{R}^{\circ}\left[{ }^{17}\right]$.

- Under $100 \%$ of $\mathrm{O}_{2}(1 \mathrm{bar}$ ), the oxidation is "fast", which is presumably due to slow termination, which involves higher radical concentration and faster oxidation process. It suggests that terminations involving $\mathrm{POO}^{\circ}$ are less efficient than those involving $\mathrm{P}^{\circ}$. 


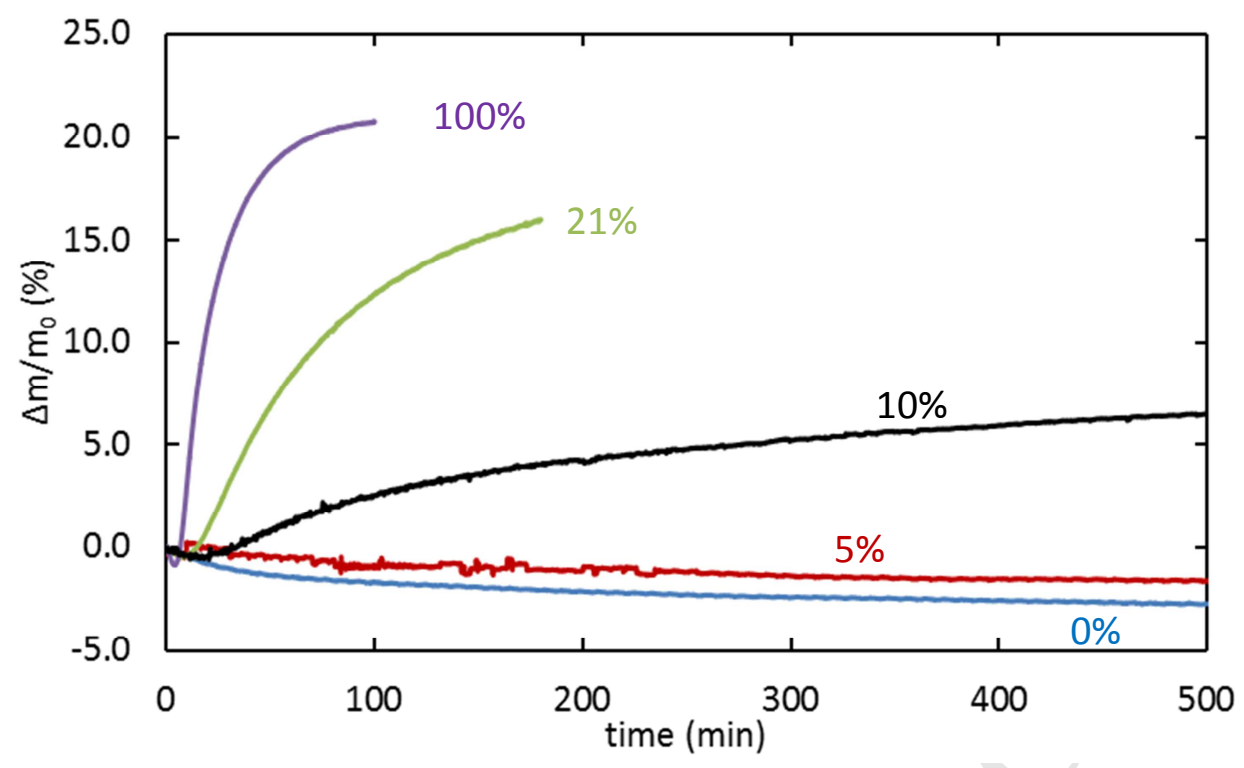

Figure 4. TGA at $120^{\circ} \mathrm{C}$ under several oxygen pressures.

\section{Hydroperoxide changes}

During polymer oxidation, hydroperoxides $(\mathrm{POOH})$ are both formed and consumed. Their buildup results for example in the auto-acceleration observed during oxidation of hydrocarbon polymers $\left[{ }^{18}\right]$. Assessing the changes in their concentration during ageing is thus very valuable for understanding some kinetic aspects of the oxidation $\left[{ }^{19}\right]$.

Hydroperoxides in situ generated in DSC cell during an isothermal step under pure $\mathrm{O}_{2}$ were quantified by a ramp under nitrogen from 50 to $250^{\circ} \mathrm{C}$ (see "EXPERIMENTAL"). This procedure has two advantages: (1) increase the concentration in $\mathrm{POOH}$ compared to ageing under air, (2) avoid uncertainties linked to short ageing times at high temperatures. The orders of magnitude of concentrations are consistent with those reported in [ $\left.{ }^{5}\right]$. Figure 5 presents the heating part of thermograms for samples with various durations of the isotherm under oxygen at $90^{\circ} \mathrm{C}$. 


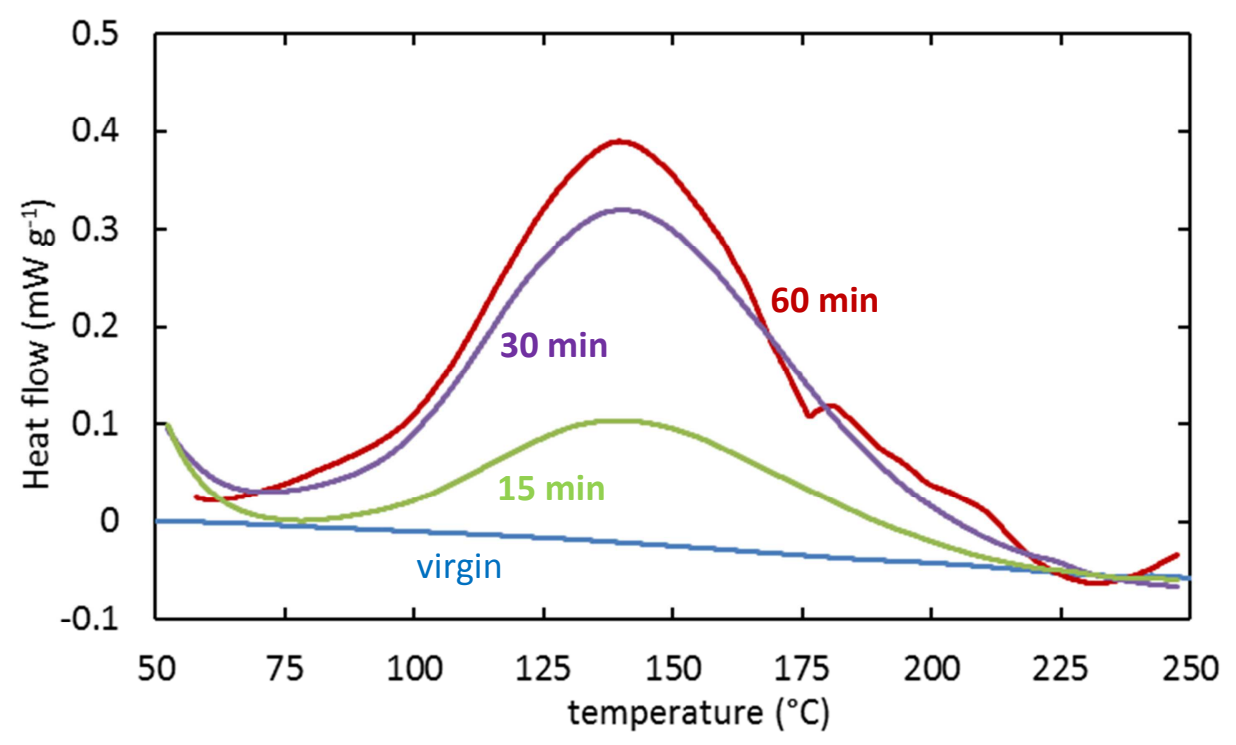

Figure 5. DSC exotherm for pDCPD aged in situ at $90^{\circ} \mathrm{C}$ during 15,25 and $30 \mathrm{~min}$.

Their shape can be commented as follows:

- no exothermal signal is observed during the cooling meaning that the decomposition of $\mathrm{POOH}$ is negligible during this stage. The same was observed for other in situ ageing temperatures.

- the "classical» exothermal signal centered at $140^{\circ} \mathrm{C}$ corresponding to hydroperoxides decomposition process $\left[{ }^{5},{ }^{19},{ }^{20}, 1\right]$ is observed during the subsequent heating. The changes in enthalpies for the exothermal signals at each temperature are plotted in Figure 6. Taking $\Delta \mathrm{H}_{\mathrm{OOH}} \sim 440$ $\mathrm{kJ} \mathrm{mol}^{-1}\left[{ }^{5}\right]$, the concentration in $\mathrm{POOH}$ exceeds $2 \mathrm{~mol} \mathrm{~kg}^{-1}$ in the temperature range under study, i.e. much more than in other thermally oxidized hydrocarbon polymers $\left[{ }^{19}, 22\right]$.

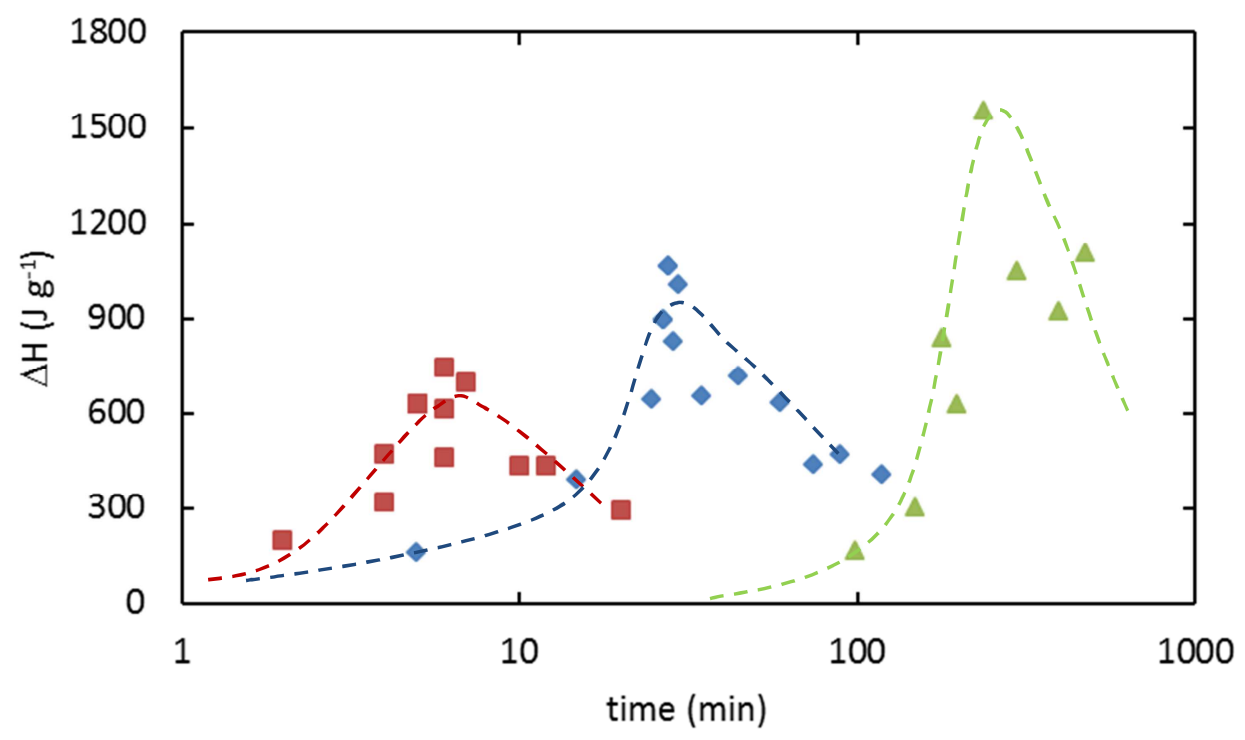

Figure 6. Hydroperoxides build-up curves at à $120(\boldsymbol{\square}), 90(\bullet)$ and $60^{\circ} \mathrm{C}(\boldsymbol{\Delta})$ under 1 bar of $\mathrm{O}_{2}$. 


\section{ACCEPTED MANUSCRIPT}

The plot of maximal enthalpies values in a Arrhenius diagram (Figure 7) shows an apparent activation energy ca $-15 \mathrm{~kJ} \mathrm{~mol}^{-1}$. It means that hydroperoxides are less stable when increasing temperature.

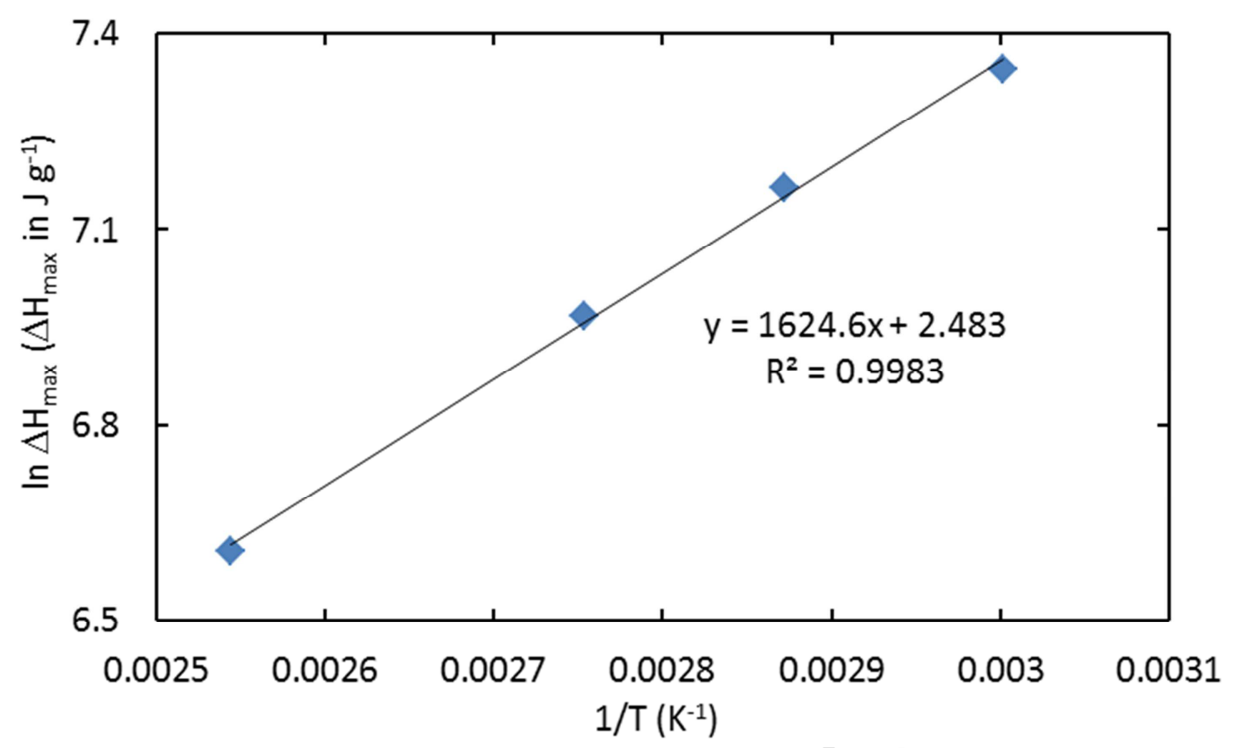

Figure 7. Arrhenius plot of maximal enthalpy for thermal decomposition of hydroperoxides.

\section{Oxygen transport properties}

Oxygen permeation tests were recorded on $175 \mu \mathrm{m}$ stabilized thick films in order to minimize the oxidation during the measurement (i.e. that a part of oxygen is consumed by thermal oxidation, inducing a misestimating of its diffusivity) and its consequences on the permeation properties $\left[{ }^{23}\right]$. The absence of mass increase revealing oxidation in the timescale of the permeation measurement was checked by TGA. 


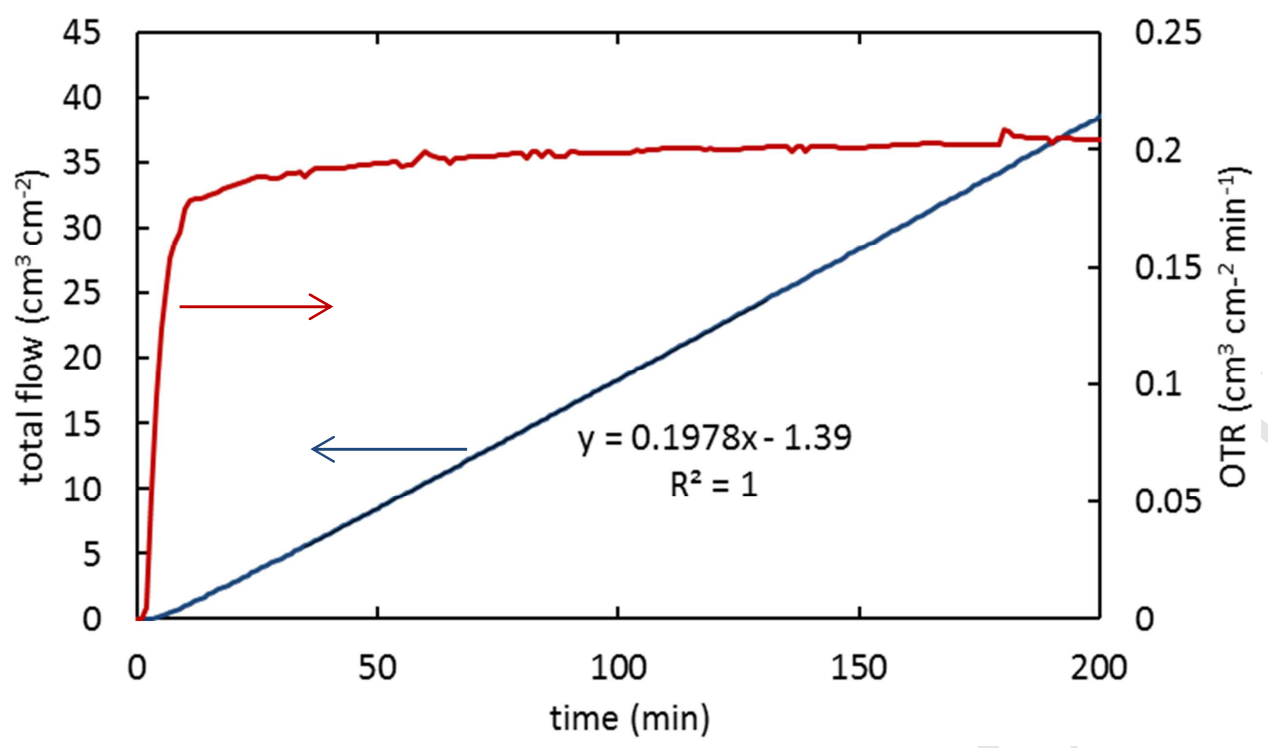

Figure 8. Oxygen permeation curve and its derivative (OTR) at $50^{\circ} \mathrm{C}$ for a $175 \mu \mathrm{m}$ thick film.

Diffusivities were estimated from time lag value (see "EXPERIMENTAL"). They seem to follow an Arrhenius law (Figure 9). The activation energy is ca $15 \mathrm{~kJ} \mathrm{~mol}^{-1}$ as expected for amorphous glassy polymers $\left[{ }^{12},{ }^{24}, 25\right]$.

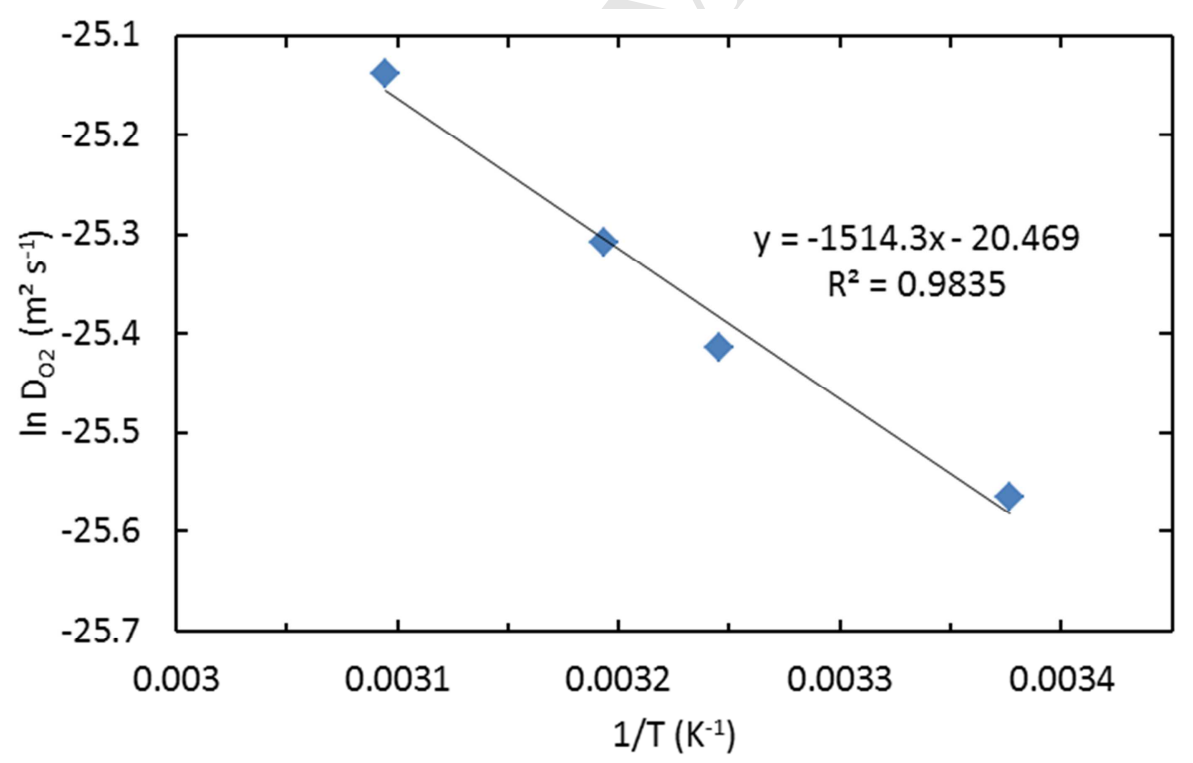

Figure 9. Arrhenius diagram of oxygen diffusivity.

The solubility (expressed $\mathrm{S}$ in $\mathrm{m}^{3}(\mathrm{STP}) \mathrm{m}^{-3} \mathrm{~Pa}^{-1}$ ) was measured from the derivate of the Oxygen Total Rate (OTR) using the formula:

$$
S=\frac{O T R \times L}{D_{O 2} \cdot P_{O 2}}
$$


where $\mathrm{P}_{\mathrm{O} 2}$ is the external oxygen pressure ( 1 bar).

It was shown to remain almost constant with temperature (ca $10^{-7} \mathrm{~mol} \mathrm{I}^{-1} \mathrm{~Pa}^{-1}$ ). Interestingly, the permeability of pDCPD seems to be in the low range among the hydrocarbon polymers (Table 1 ), despite the possible experimental uncertainties affecting the values of oxygen solubility for example. This will be commented regarding the diffusion limited oxidation aspects in the "DISCUSSION" section.

\begin{tabular}{|c|c|c|c|}
\hline & $D_{02}$ & $\mathrm{~S}_{02}$ & $\mathrm{Pe}$ \\
\hline & $\left(\mathrm{cm}^{2} \mathrm{~s}^{-1}\right)$ & $\left(\mathrm{cm}^{3}(\mathrm{STP}) \mathrm{cm}^{-3} \operatorname{bar}^{-1}\right)$ & $\left(\mathrm{cm}^{3}(\mathrm{STP}) \mathrm{cm}^{-1} \mathrm{~s}^{-1} \mathrm{bar}^{-1}\right)$ \\
\hline BR & $1.5 \times 10^{-6}$ & 0.097 & $1.46 \times 10^{-7}$ \\
\hline LDPE & $4.6 \times 10^{-7}$ & 0.046 & $2.12 \times 10^{-8}$ \\
\hline poly(trans-1,4-isoprene) & $7.0 \times 10^{-7}$ & 0.102 & $7.14 \times 10^{-8}$ \\
\hline pDCPD & $8.0 \times 10^{-8}$ & 0.225 & $1.80 \times 10^{-8}$ \\
\hline
\end{tabular}

Table 1. Oxygen permeability, diffusivity, solubility values at $298 \mathrm{~K}$ for pDCPD (this work) and for other polymers $\left[{ }^{24}\right]$. 
DISCUSSION

This section aims to comment the oxidative stability of PDCPD for thin unstabilized films and what it could be for thick samples used in industrial applications. Three points will be discussed:

(1) the high oxidation rate of pDCPD in thin samples and the occurrence of degradation in thick samples where oxygen diffusion is the limiting step,

(2) the low activation energy of the oxidation process, for predicting the stability during the low temperature thermal ageing, and linked to the influence of physical state of pDCPD matrix,

(3) the stability of pDCPD hydroperoxides, linked to the induction period duration, and the influence of residual Ring Opening Metathesis Polymerization catalysts.

1. On the oxidizability of pDCPD and the influence of oxygen diffusion

PDCPD is obtained by metathesis of dicyclopentadiene (Scheme 1) giving a linear polymer $\left[{ }^{26},{ }^{27}\right]$ crosslinked by polymerization self-heating $\left[{ }^{28},{ }^{29}\right]$. The concentration in allylic $\mathrm{C}-\mathrm{H}$ groups is $[\mathrm{PH}]=$ $4 / \mathrm{M}_{0} \sim 30 \mathrm{~mol} \mathrm{~kg}^{-1}$ in PDCPD instead of 37 in butadiene rubber.
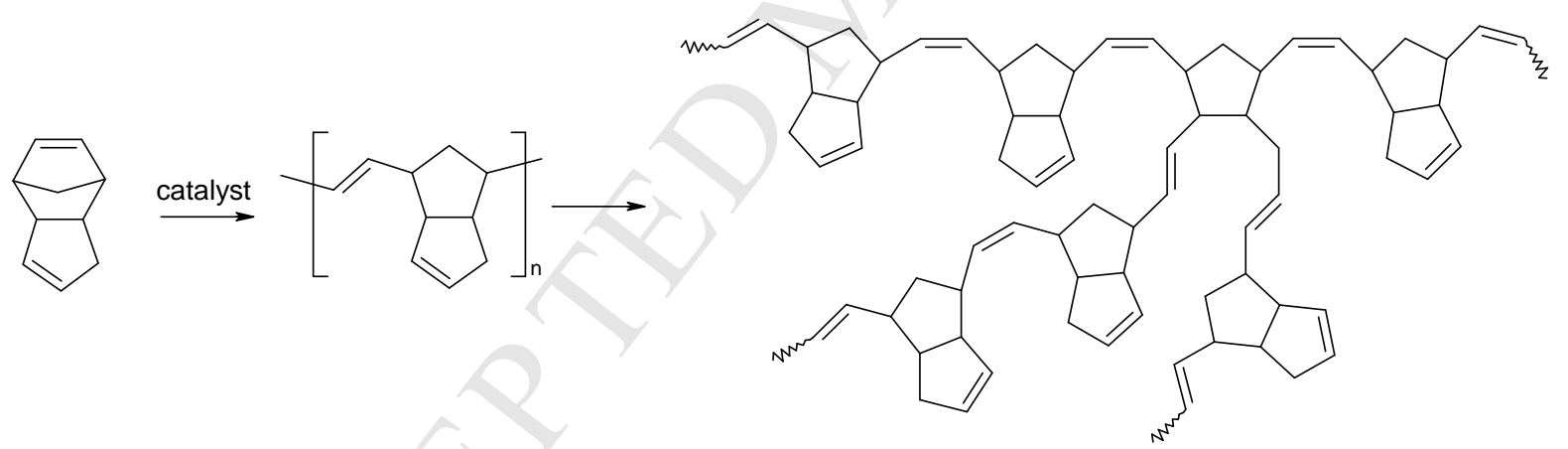

Scheme 1. Structure of polydicyclopentadiene.

Nevertheless, the mass uptakes at the plateau (Figure 2) are higher in pDCPD (ca 30\%) than those of $\mathrm{BR}$ (from ca $13 \%$ at $120^{\circ} \mathrm{C}$ to more than $25 \%$ at moderate temperature e.g. $60^{\circ} \mathrm{C}$ ). Together with the plot of maximal rates for mass uptake (Figure 3 ), it shows that PDCPD is more oxidizable than BR. The "oxidizability" is here expressed as the maximal rate for mass increase and is given by the ratio $\mathrm{k}_{3}^{2}[\mathrm{PH}]^{2} / \mathrm{k}_{6}$. $[\mathrm{PH}]$ is actually lower for pDCPD than BR. In other words, it means that the combination of rate constants $k_{3}^{2} / k_{6}$ is higher for PDCPD than for $B R\left(k_{3}\right.$ and $k_{6}$ are respectively the rate constant for propagation and termination - see later). The most possible explanation for us will be given in the next paragraphs. 
From a kinetic point of view, the Diffusion Limited Oxidation means that oxygen diffusion is the limiting step. In the case of polybutadiene oxidation, it results in the existence of an oxidized layer with a thickness ca $20 \mu \mathrm{m}$ at $120^{\circ} \mathrm{C}\left[{ }^{11}\right]$. pDCPD displays a lower oxygen permeability (Table 1 ) together with a higher oxidation rate (Figure 3 ) which explain why its oxidized layers are thinner: ca $10 \mu \mathrm{m}$ at $150^{\circ} \mathrm{C}$ and $15 \mu \mathrm{m}$ at $120^{\circ} \mathrm{C}$ (Figure 1 ).

The thickness of oxidized layer (denoted by TOL) can be expressed from the oxygen diffusivity $\left(D_{02}\right)$ and concentration $\left(\left[\mathrm{O}_{2}\right]\right)$ and the value of oxidation rate $\mathrm{r}_{\mathrm{Ox}}\left[{ }^{30}\right]$ :

$$
T O L^{2}=\frac{D_{O 2}}{r_{O X} /\left[O_{2}\right]}
$$

The maximal oxidation rate $\left(r_{o x}\right)$ and the maximal rate for mass increase $\left(r_{m}\right)$ are strongly linked (see "APPENDIX") and their activation energies are undoubtedly very close. If $D_{02}$ and $r_{0 x}$ (or $r_{m}$ ) obey an Arrhenius law (Figures 3 and 9), and $\left[\mathrm{O}_{2}\right]$ does not depend on temperature (see '3. Oxygen transport properties'), the activation energy for TOL expressing its temperature dependence is given by:

$$
E_{T O L}=\frac{1}{2} \cdot\left(E_{D}-E_{O X}\right)
$$

where $E_{D}$ and $E_{O X}$ are respectively the activation energies for diffusion and for oxidation. One obtains:

$$
\mathrm{E}_{\mathrm{TOL}}=0.5 \times(15-45) \sim-15 \mathrm{~kJ} \mathrm{~mol}^{-1}
$$

It means that TOL decreases slightly with temperature as classically observed [ $\left.{ }^{31}\right]$. If TOL is ca $10 \mu \mathrm{m}$ at $150^{\circ} \mathrm{C}$, it would be ca $50-75 \mu \mathrm{m}$ at room temperature for PDCPD i.e. significantly lower than for epoxies $\left[{ }^{32}\right]$ or unsaturated polyesters $\left[{ }^{13}\right]$. Besides this practical point, it confirms that oxidation is not controlled by diffusion for discussing all the above presented results and extracting reliable kinetics parameters $\left[{ }^{8}\right]$.

2. On the activation energy of oxidation process

Experimental results for oxidation rate highlight an apparent activation energy of $45 \mathrm{~kJ} \mathrm{~mol}^{-1}$ (Figure 3) which is very low compared to others common polymers $\left[{ }^{11},{ }^{13},{ }^{19}\right]$. In order to propose an explanation, let us assume that oxidation under 1 bar $\mathrm{O}_{2}$ can be approximated by the following mechanistic scheme: 


$$
\begin{array}{ll}
\mathrm{POOH} \rightarrow 2 \mathrm{P}^{\circ}+\gamma_{1} \cdot \mathrm{P}=\mathrm{O}+\mathrm{H}_{2} \mathrm{O}+\gamma_{2} \cdot \text { volatile } & \mathrm{k}_{1} \\
\mathrm{P}^{\circ}+\mathrm{O}_{2} \rightarrow \mathrm{POO} & \mathrm{k}_{2} \\
\mathrm{POO}^{\circ}+\mathrm{PH} \rightarrow \mathrm{POOH}+\mathrm{P}^{\circ} & \mathrm{k}_{3} \\
\mathrm{POO}^{\circ}+\mathrm{POO}^{\circ} \rightarrow \text { inactive product }+\mathrm{O}_{2} & \mathrm{k}_{6}
\end{array}
$$

As justified elsewhere $\left[{ }^{33}\right]$, the equation for $\mathrm{POOH}$ decomposition is actually a kinetically equivalent balance equation for the $\mathrm{POOH} \rightarrow \mathrm{PO}^{\circ}+{ }^{\circ} \mathrm{OH}$ reaction followed by the almost instantaneous conversion of intermediary species $\left(\mathrm{PO}^{\circ}, \mathrm{HO}^{\circ}\right.$ ) into "stable" by-products (alkyl radicals $\mathrm{P}^{\circ}$, carbonyls $\mathrm{P}=\mathrm{O}$, volatiles $\mathrm{V}$ ).

Assuming that there is no volatile loss (see Figure 2), it is possible (see "APPENDIX") to show that:

$$
r_{O X}=14 \times \frac{1}{\rho} \cdot \frac{k_{3}^{2}}{2 k_{6}}[P H]^{2}
$$

$r_{\mathrm{Ox}}$ obeys thus Arrhenius law with an apparent activation energy given by $\mathrm{E}_{\mathrm{OX}}=2 \mathrm{E}_{3}-\mathrm{E}_{6} \sim 45 \mathrm{~kJ} \mathrm{~mol}^{-1}$ for PDCPD instead of $85 \mathrm{~kJ} \mathrm{~mol}^{-1}$ for butadiene rubber (Figure 3).

The activation energy for the propagation reaction $\mathrm{POO}^{\circ}+\mathrm{PH} \rightarrow \mathrm{POOH}+\mathrm{P}^{\circ}$ is $\mathrm{ca} 65 \mathrm{~kJ} \mathrm{~mol}^{-1}$ for $\mathrm{BR}$ $\left[{ }^{11}\right]$. Since the rate of this reaction mainly depends on the strength of the $\mathrm{C}-\mathrm{H}$ bond undergoing the radical attack $\left[{ }^{34}\right]$, it would be the same for PDCPD where oxidizable groups are also located in $\alpha$ position of double bond. It induces that:

$$
\mathrm{E}_{6} \sim 130-45=85 \mathrm{~kJ} \mathrm{~mol}^{-1}
$$

This value is higher than for the termination by disproportionation between two low molar mass peroxyl radicals $\left.{ }^{35}\right]$ for which Denisov reported that $\mathrm{E} \sim 20 \mathrm{~kJ} \mathrm{~mol}^{-1}$ when mobility of reactants is not the limiting step (NB: polybutadiene, which is rubbery state, can be considered as an intermediate case between pDCPD and liquid model compounds).

The rate constant for reactions involving macromolecular substrates is usually expressed by $\left[{ }^{36},{ }^{37}\right]$ :

$$
\frac{1}{k}=\frac{1}{k_{R}}+\frac{1}{k_{D}}
$$


$k_{D}$ is given by the Smoluchowski equation $\left[{ }^{38}\right]$ :

$$
k_{D}=4 \pi \cdot r_{0} \cdot\left(D_{A}+D_{B}\right) \cdot N_{a}
$$

where $r_{0}$ is the capture radius i.e. the distance below which the reaction constant is expected to depend only on thermochemistry or steric hindrance.

Taking the value for cyclopentene peroxyl $\left[{ }^{35}\right]: k_{R}=6.3 \times 10^{7} \times \exp (-4.2 / R T)$, it gives:

$$
k_{D}=3.6 \times 10^{11} \times \exp (-80400 / R T)
$$

Diffusion controlled termination is a complicated issue already addressed in the case of polymerization $\left[{ }^{39},{ }^{40},{ }^{41}\right]$ or irradiation $\left[{ }^{42}{ }^{43}\right]$. It led to many theoretical developments but a scarce estimation of the involved kinetic parameters. For linear macromolecules, De Gennes $\left[{ }^{44},{ }^{45}\right]$ showed that the diffusivity of reactive sites was linked to the mechanism of chain migration i.e. Rouse for non-entangled chains and reptation for entangled ones. The mechanism responsible for mobility of reactive units would translate into the temperature dependence of the termination constant $k_{D}$.

The mobility in networks was intensively studied for example by dielectric spectroscopy $\left[\begin{array}{l}46,47,48,49 \\ ,\end{array},[0]\right.$. To summarize:

- the $\log$ (relaxation frequency) vs $1 / T$ diagram for $\alpha$ relaxation displays a curvature. When $T>T_{g}$ (typically $\mathrm{T}>\mathrm{T}_{\mathrm{g}}+50^{\circ} \mathrm{C}$ ), it becomes linear with an apparent activation energy about $200 \mathrm{~kJ} \mathrm{~mol}^{-1}$; - the sub-glassy relaxations ( $\beta$ and $\gamma$ ) linked to local motions of a monomer or a group of atoms strictly obeys an Arrhenius law with an activation energy ca $60-80 \mathrm{~kJ} \mathrm{~mol}^{-1}$.

In other words, our results suggest that termination reactions in glassy PDCPD are controlled by local motions associated to sub-glassy (or $\beta$ ) relaxation being the most "effective" in glassy state. It could also explain why curves expressing the oxidizability of BR and PDCPD converge at $\left(T_{g}\right)_{P D C P D}$ (Figure 3 ) at which both materials are unsaturated polymers oxidized in rubbery state. The nature and the temperature dependence of relaxation in PDCPD remains, however, an open question.

3. On the stability of hydroperoxides 
Metathesis polymerization requires the use of organometallic catalysts in relatively high concentration (typically 100-1000 ppm [ $\left.{ }^{51}\right]$ ) compared to the case of polyolefins $\left[{ }^{52}\right]$ or elastomers. These one could accelerate the thermal decomposition of hydroperoxides, as discussed here, using the following kinetic description:

$$
\begin{array}{ll}
\mathrm{POOH} \rightarrow \mathrm{PO}^{\circ}+{ }^{\circ} \mathrm{OH} & \mathrm{k}_{0} \\
\mathrm{POOH}+\mathrm{M}^{\mathrm{n}+} \rightarrow \mathrm{PO}^{\circ}+\mathrm{M}^{(\mathrm{n}+1)+}-\mathrm{OH} & \mathrm{k}_{\mathrm{c} 1} \\
\mathrm{POOH}+\mathrm{M}^{(\mathrm{n}+1)+}-\mathrm{OH} \rightarrow \mathrm{POO}^{\circ}+\mathrm{M}^{\mathrm{n}+}+\mathrm{H}_{2} \mathrm{O} & \mathrm{k}_{\mathrm{c} 2}
\end{array}
$$

so that:

$$
\frac{d[\mathrm{POOH}]}{d t}=-k_{0}[\mathrm{POOH}]-k_{c 1}[\mathrm{POOH}]\left[\mathrm{M}^{n+}\right]-k_{c 2}[\mathrm{POOH}]\left[M^{(n+1)+}-\mathrm{OH}\right]
$$

The steady state hypothesis on $\mathrm{M}^{\mathrm{n+}}$ gives: $\quad \mathrm{k}_{\mathrm{c} 1}\left[\mathrm{M}^{\mathrm{nt}}\right]=\mathrm{k}_{\mathrm{c} 2}\left[\mathrm{M}^{(\mathrm{n}+1)+}-\mathrm{OH}\right]$

and: $\frac{d[\mathrm{POOH}]}{d t}=-k_{0}[\mathrm{POOH}]-k_{c a t}[\mathrm{POOH}]\left[\mathrm{M}^{n+}\right]=-\left(k_{0}+k_{c a t}\left[\mathrm{M}^{n+}\right]\right) \cdot[\mathrm{POOH}]$

Eq. 10 is consistent with the equation $\left[{ }^{53}\right]: k_{1}=k_{0}+K_{c}[\text { catalyst }]^{x}$ where $k_{1}$ is the observed pseudo rate constant in the presence of catalyst, $k_{0}$ is that for the uncatalyzed reaction, $K_{c}$ is the catalytic constant and $\mathrm{x}$ the order of the reaction with respect to catalyst. It shows that catalysts accelerate the decomposition of $\mathrm{POOH}$ by a concentration effect $\left[{ }^{54}\right]$ without changing the order of the reaction as illustrated in $\left[{ }^{55}, 56,57\right]$. It can thus be shown that:

$$
[\mathrm{POOH}]=\frac{k_{3}^{2}[\mathrm{PH}]^{2}}{k_{6} \cdot\left(k_{u}+k_{c a t}\left[M^{n+}\right]\right)}
$$

On the assumption that $\mathrm{k}_{\mathrm{u}} \ll \mathrm{k}_{\mathrm{cat}}\left[\mathrm{M}^{\mathrm{n}+}\right]$, it gives:

$$
[P O O H]=\frac{k_{3}^{2}[P H]^{2}}{k_{6} \cdot k_{c a t}\left[M^{n+}\right]}=\frac{k_{3}^{2}[P H]^{2}}{k_{6} \cdot k_{1}}
$$

It leads to:

$$
E_{\mathrm{POOH}}=2 E_{3}-E_{1}-E_{6}
$$

Where $\mathrm{E}_{\mathrm{POOH}}$ comes from Figure 7. It gives: $\mathrm{E}_{1} \sim 130-75+15 \sim 70 \mathrm{~kJ} \mathrm{~mol}^{-1}$ which is less than in PE $\left(134 \mathrm{~kJ} \mathrm{~mol}^{-1}\right)$ or BR $\left(140 \mathrm{~kJ} \mathrm{~mol}^{-1}\right)$. 
The relationship between activation energy decrease and catalysts content did not receive, to our knowledge, any theoretical formalism. However, the catalysts effect on the decomposition of hydroperoxides is for example illustrated in the case of:

- $\mathrm{HOOH}$ where $E_{1}$ drops from 180 to 100 for catalyzed decomposition by copper complexes $\left[{ }^{58}\right]$,

- cumene hydroperoxide where $E_{1}$ falls from $100 \mathrm{~kJ} \mathrm{~mol}^{-1}\left[{ }^{59}, 60\right]$ to values less than $75 \mathrm{~kJ} \mathrm{~mol}^{-1}$ in presence of copper $\left[{ }^{61}\right]$,

- tert-butyl hydroperoxide where $E_{1}=155 \mathrm{~kJ} \mathrm{~mol}^{-1}$ for unimolecular decomposition ${ }^{62}$ ] decreases to $60-80 \mathrm{~kJ} \mathrm{~mol}^{-1}\left[{ }^{63}\right]$ in presence of cobalt(II) or cobalt(III) salts.

The order of magnitude of activation energy for initiation $\left(E_{1}\right)$ is in good agreement with literature values suggesting that metallic catalysts accelerate the oxidation of PDCPD due to the faster decomposition of $\mathrm{POOH}$. 


\section{CONCLUSIONS}

The thermal oxidation of unstabilized thin polydicyclopentadiene films in glassy state was studied by gravimetry (TGA), and hydroperoxides titration. TGA curves display a continuous increase with a short induction period and a ca $30 \%$ plateau which is almost constant with temperature. Hydroperoxides were observed in a high amount (ca $2 \mathrm{~mol} \mathrm{l}^{-1}$ ). The kinetic analysis of these results allowed activation energies for initiation and termination processes to be derived. The activation energy for initiation was found to be lower than observed for other hydrocarbon substrates, which was discussed from the presence of organometallic polymerization catalysts favoring the hydroperoxide decomposition into radicals. The activation energy for termination was found to be higher than those of model compounds, which was discussed from the relatively low molecular mobility in the glassy state. However, those facts are counterbalanced by the low value for thickness of oxidized layer (observed to be lower than $10 \mu \mathrm{m}$ at $150^{\circ} \mathrm{C}$ and estimated ca $50 \mu \mathrm{m}$ at room temperature). The degradation is therefore confined in a thin superficial layer where there is obviously no thermally induced volatile emission and no subsequent shrinkage but where crosslinking is the main consequence of degradation $\left[{ }^{64}\right]$. PDCPD is hence expected to be suitable for long term use in severe conditions such as those encountered for offshore applications $\left[{ }^{64}\right]$.

\section{ACKNOWLEDGEMENTS}

Carnot ARTS and Carnot EDROME are gratefully acknowledged for having granted the OsMoSE research project (2014).

Agence Nationale de la Recherche is gratefully acknowledged for having grated the VRPOM research project (2016-2019). 


\section{APPENDIX}

From the mechanistic scheme presented in " 2 . On the activation energy of oxidation process", the kinetics of mass uptake is given by:

$$
\frac{d m / m_{0}}{d t}=\frac{1}{\rho} \cdot\left(-k_{1}[\mathrm{POOH}] \cdot M_{v}-k_{1}[\mathrm{POOH}] \cdot M_{H 2 O}+k_{2}\left[P^{\circ}\right]\left[O_{2}\right] \cdot M_{O 2}-k_{6}\left[\mathrm{POO}^{\circ}\right]\left[\mathrm{POO}^{\circ}\right] \cdot M_{O 2}\right)
$$

It can be shown, using the classical steady state approximations:

for $\mathrm{POO}^{\circ}: \quad \mathrm{k}_{2}\left[\mathrm{P}^{\circ}\right]\left[\mathrm{O}_{2}\right]=\mathrm{k}_{3}\left[\mathrm{POO}^{\circ}\right][\mathrm{PH}]+2 \mathrm{k}_{6}\left[\mathrm{POO}^{\circ}\right]^{2}$

for $\mathrm{POOH}: \quad \mathrm{k}_{3}\left[\mathrm{POO}^{\circ}\right][\mathrm{PH}]=\mathrm{k}_{1}[\mathrm{POOH}]$

for $\mathrm{P}^{\circ}+\mathrm{POO}^{\circ}: \mathrm{k}_{1}[\mathrm{POOH}]=\mathrm{k}_{6}\left[\mathrm{POO}^{\circ}\right]^{2}$

The steady state assumption leads to:

$$
\begin{aligned}
& {[\mathrm{POOH}]_{S}=\frac{k_{3}^{2}[\mathrm{PH}]^{2}}{k_{1} k_{6}}} \\
& r_{m}=\frac{d m / m_{0}}{d t}=\frac{1}{\rho} \cdot k_{1}[\mathrm{POOH}]\left(14-M_{v}\right)=\frac{k_{3}{ }^{2}[P H]^{2}}{\rho . k_{6}} \cdot\left(14-M_{v}\right) \\
& r_{O X}=\frac{d\left[\mathrm{O}_{2}\right]}{d t}=-k_{2}\left[\mathrm{P}^{\circ}\right]\left[\mathrm{O}_{2}\right]+k_{6}\left[\mathrm{POO}^{\circ}\right]^{2}=-k_{3}\left[\mathrm{POO}^{\circ}\right][\mathrm{PH}]-k_{6}\left[\mathrm{POO}^{\circ}\right]^{2} \\
& =-2 k_{6}\left[P O O^{\circ}\right]^{2}=\frac{-2 k_{3}{ }^{2}[P H]^{2}}{k_{6}}
\end{aligned}
$$

It means that the activation energy of mass uptake and oxidation both are equal to $2 E_{3}-E_{6}$. 


\section{REFERENCES}

${ }^{1}$ T.R. Waite. Theoretical treatment of the kinetics of diffusion-limited reactions. Physical Reviews 107 (1957) 463-470.

${ }^{2}$ T.R. Waite. General theory of bimolecular reaction rates in solids and liquids. J. Chem. Phys. 28 (1958) 103106.

${ }^{3}$ Y. Chauvin. Review: Olefin Metathesis: The Early Days (Nobel Lecture). Angew. Chem. Int. Ed. 45 (2006) 37403747.

${ }^{4}$ R.H. Grubbs. Olefin-Metathesis Catalysts for the Preparation of Molecules and Materials (Nobel Lecture 2005). Adv. Synth. \& Catal. 349 (2007) 34-40.

${ }^{5}$ E. Richaud, P.Y. Le Gac, J. Verdu. Thermooxidative aging of polydicyclopentadiene in glassy state. Polym. Degrad. Stab. 102 (2014) 95-104.

${ }^{6}$ M.L. Binet, S. Commereuc, V. Verney. Thermo-oxidation of polyterpenes: influence of the physical state. Eur. Pol. J. 36 (2000) 2133-2142.

${ }^{7}$ F.R. Mayo. Relative Reactivities in Oxidations of Polypropylene and Polypropylene Models. Macromolecules 11 (1978) 942-946.

8 M. Celina. Review of polymer oxidation and its relationship with materials performance and lifetime prediction. Polym. Degrad. Stab. 98 (2013) 2419-2429.

${ }^{9}$ J. Crank. The Mathematics of Diffusion. Second edition. Clarenson Press. Oxford. 1975. Chap. 4. Diffusion in a plane sheet. Pages 44-68.

${ }^{10}$ A. Guinault, C. Sollogoub, V. Ducruet, S. Domenek. Impact of crystallinity of poly (lactide) on helium and oxygen barrier properties. Eur. Pol. J.I 48 (2012) 779-788.

${ }^{11}$ M. Coquillat, J. Verdu, X. Colin, L. Audouin, R. Nevière. Thermal oxidation of polybutadiene. Part 1: Effect of temperature, oxygen pressure and sample thickness on the thermal oxidation of hydroxyl-terminated polybutadiene. Polym. Degrad. Stab. 92 (2007) 1326-1333.

${ }^{12}$ C. Damian, E. Espuche, M. Escoubes. Influence of three ageing types (thermal oxidation, radiochemical and hydrolytic ageing) on the structure and gas transport properties of epoxy-amine networks. Polym. Degrad. Stab. 72 (2001) 447-458.

13 J.S. Arrieta, E. Richaud, B. Fayolle, F. Nizeyimana. Thermal oxidation of vinyl ester and unsaturated polyester resins. Polym. Degrad. Stab. 129 (2016) 142-155.

14 J. Rychly, L. Matisova-Rychla, K. Csmorova, L. Achimsky, L. Audouin, A. Tcharkhtchi, J. Verdu. Kinetics of mass changes in oxidation of polypropylene. Polym. Degrad. Stab. 58 (1997) 269-274.

${ }^{15}$ P.Y. Le Gac, G. Roux, J. Verdu, P. Davies, B. Fayolle. Oxidation of unvulcanized, unstabilized polychloroprene: A kinetic study. Polym. Degrad. Stab. 109 (2014) 175-183.

${ }^{16}$ E. Richaud, F. Farcas, P. Bartoloméo, B. Fayolle, L. Audouin, J. Verdu. Effect of oxygen pressure on the oxidation kinetics of unstabilised polypropylene. Polym. Degrad. Stab. 91 (2006) 398-405.

${ }^{17}$ N.M. Emanuel, A.L. Buchachenko. Chemical Physics of Polymer Degradation and Stabilization (New Concepts in Polymer Science). Utrecht: VNU Science Press, 1987, p. 84. 
${ }_{18} \mathrm{~J}$. Verdu. On the autoaccelerated character of the branched oxidation of polyolefins. Macromolecular Symposia 115 (1997) 165-180.

${ }^{19}$ E. Richaud, F. Farcas, B. Fayolle, L. Audouin, J. Verdu. Hydroperoxide build-up in the thermal oxidation of polypropylene - A kinetic study. Polym. Degrad. Stab. 92 (2007) 118-124.

${ }^{20}$ Y. Ouldmetidji, L. Gonon, S. Commereuc, V. Verney. A differential scanning calorimetry method to study polymer photoperoxidation. Polymer Test. 20 (2001) 765-768.

${ }^{21} \mathrm{~J}$ Mallégol, L Gonon, S Commereuc, $\mathrm{V}$ Verney. Thermal (DSC) and chemical (iodometric titration) methods for peroxides measurements in order to monitor drying extent of alkyd resins. Progr. Org. Coat. 41 (2001) 171-176.

${ }^{22}$ M. Coquillat, J. Verdu, X. Colin, L. Audouin, R. Nevière. Thermal oxidation of polybutadiene. Part 2: Mechanistic and kinetic schemes for additive-free non-crosslinked polybutadiene. Polym. Degrad. Stab. 92 (2007) 1334-1342.

${ }^{23}$ J.-L. Gardette, A. Colin, S. Trivis, S. German, S. Therias. Impact of photooxidative degradation on the oxygen permeability of poly(ethyleneterephthalate). Polym. Degrad. Stab. 103 (2014) 35-41.

${ }^{24}$ D.W. Van Krevelen, K. Te Nijenhuis. Properties of Polymers. Their Correlation with Chemical Structure; Their Numerical Estimation and Prediction from Additive Group Contributions. Fourth, completely revised edition. Elsevier Amsterdam. 2009. Chap. 18. Properties Determining Mass Transfer In Polymeric Systems. Table 18.6. Pages 655-702.

${ }^{25}$ S. Pauly The radiation resistance of thermoset plastics-III. Oxygen permeation experiments. Int. J. Rad. Appl. Instr. C-Rad. Phys. Chem. 39 (1992) 269-272.

${ }^{26}$ V. Lapinte, L. Fontaine, V. Montembault, I. Campistron, D. Reyx. Ring-opening metathesis polymerization (ROMP) of isomerically pure functional monomers and acyclic diene metathesis depolymerization (retroADMET) of functionalized polyalkenamers. J. Mol. Catal. A-Chem. 190 (2002) 117-129.

${ }^{27}$ P. de Frémont, H. Clavier, V. Montembault, L. Fontaine, S.P. Nolan. Ruthenium-indenylidene complexes in ring opening metathesis polymerization (ROMP) reactions. J. Mol. Catal. A-Chem. 283 (2008) 108-113.

${ }^{28}$ M.J. Abadie, M. Dimonie, Christine Couve, V. Dragutan. New catalysts for linear polydicyclopentadiene synthesis. Eur. Pol. J. 36 (2000) 1213-1219.

${ }^{29}$ D. Dimonie, M. Dimonie, V. Munteanu, H. lovu, J. Couve, M.J. Abadie. Nature of the first exothermic peak on the DSC curve of linear polydicyclopentadiene obtained with a special catalytic system. Polym. Degrad. Stab. 70 (2000) 319-324.

${ }^{30}$ L. Audouin, V. Langlois, J. Verdu, J. C. M. de Bruijn. Role of oxygen diffusion in polymer ageing: kinetic and mechanical aspects. J. Mater. Sci. 29 (1994) 569-583.

${ }^{31}$ M. Celina, J. Wise, D.K. Ottesen, K.T. Gillen, R.L. Clough. Correlation of chemical and mechanical property changes during oxidative degradation of neoprene. Polym. Degrad. Stab. 68 (2000) 171-184.

32 L. Olivier, N.Q. Ho, J.C. Grandidier, M.C. Lafarie-Frenot. Characterization by ultra-micro indentation of an oxidized epoxy polymer: Correlation with the predictions of a kinetic model of oxidation. Polym. Degrad. Stab. 93 (2008) 489-497.

${ }^{33}$ L. Audouin, V. Gueguen, A. Tcharkhtchi, J. Verdu. "Close loop" mechanistic schemes for hydrocarbon polymer oxidation. J. Polym. Sci. A Polym. Chem. 33 (1995) 921-927. 
${ }^{34}$ S. Korcek, J.H.B. Chenie, J.A. Howard, K.U. Ingold. Absolute Rate Constants for Hydrocarbon Autoxidation. XXI. Activation Energies for Propagation and the Correlation of Propagation Rate Constants with CarbonHydrogen Bond Strengths. Can. J. Chem. 50 (1972) 2285-2297.

${ }^{35}$ E.T. Denisov, I.B. Afanas'ev. Oxidation and Antioxidants in Organic Chemistry. and Biology, Taylor \& Francis, 2005. Chap 2. Chain Mechanism of Liquid-Phase Oxidation of Hydrocarbons. Table 2.17.

${ }^{36}$ K. Dušek. Diffusion control in the kinetics of cross-linking. Polymer Gels and Networks 4 (1996) 383-404.

${ }^{37}$ T.R. Waite. Bimolecular Reaction Rates in Solids and Liquids. J. Chem. Phys. 32 (1960) 21-23.

${ }^{38}$ M. von Smoluchowski. Versuch einer mathematischen Theorie der Koagulationskinetik kolloider Lösungen. Zeitschrift fuer physikalische Chemie 92, 1917, Pages 129-168.

${ }^{39}$ K. Ito. Radical Polymerization Rate of Methyl Methacrylate above $10 \%$ Conversion under the Condition of Predominant Transfer. Polym. J. 16 (1984) 761-769.

40 J.-N. Cardenas, K.F. O'Driscoll. High-Conversion Polymerization. I. Theory and Application to Methyl Methacrylate. J. Polym. Sci. Polym. Chem. 14 (1976) 883-897.

${ }^{41}$ T.J. Tulig, M. Tirrell. Toward a Molecular Theory of the Trommsdorff Effect. Macromolecules 14 (1981) 15011511.

42 T. Devanne, A. Bry, N. Raguin, M. Sebban, P. Palmas, L. Audouin, J. Verdu. Radiochemical ageing of an amine cured epoxy network. Part II: kinetic modelling. Polymer 46 (2005) 237-241.

${ }^{43}$ S. Shimada, Y. Hori, H. Kashiwabara. Relation between diffusion controlled decay of radicals and $\alpha$-relaxation in polyethylene and polyoxymethylene. Polymer 22 (1981) 1377-1384.

${ }^{44}$ P.G. De Gennes. Kinetics of diffusion controlled processes in dense polymer systems I. Nonentangled regime. J. Chem. Phys. 76 (1982) 3316-3321.

45 P.G. De Gennes. Kinetics of diffusion controlled processes in dense polymer systems II. Effect of entanglements. J. Chem. Phys. 76 (1982) 3322-3326.

${ }^{46}$ M. Zajac, H. Kahl, B. Schade, T. Rödel, M. Dionisio, M. Beiner. Relaxation behavior of polyurethane networks with different composition and crosslinking density. Polymer 111 (2017) 83-90.

${ }^{47}$ S. Radhakrishnan, D. Haywafw, A.J. Mackinnon, R.A. Pethrick. Investigation of Cure in Epoxy Acrylate Resins Using Rheological and Dielectric Measurements. Polym. Eng. Sci. 35 (1995) 184-189.

${ }^{48}$ G. Dlubek, E.M. Hassan, R. Krause-Rehberg, J. Pionteck. Free volume of an epoxy resin and its relation to structural relaxation: Evidence from positron lifetime and pressure-volume-temperature experiments. Phys. Rev. E 73 (2006) 031803.

49 F. Román, P. Colomer, Y. Calventus, J.M. Hutchinson. Molecular Mobility in Hyperbranched Polymers and Their Interaction with an Epoxy Matrix. Materials 9 (2016) Article 192.

${ }^{50}$ G. Polizos, E. Tuncer, A.L. Agapov, D. Stevens, A.P. Sokolov, M.K. Kidder, J.D. Jacobs, H. Koerner, R.A. Vaia, K.L. More, I. Sauers. Effect of polymer-nanoparticle interactions on the glass transition dynamics and the conductivity mechanism in polyurethane titanium dioxide nanocomposites. Polymer 53 (2012) 595-603.

${ }^{51}$ M.R. Kessler, S.R. White. Cure Kinetics of the Ring-Opening Metathesis Polymerization of Dicyclopentadiene J. Polym. Sci. Polym. Chem. 40 (2002) 2373-2383. 
52 J. Huang, G.L. Rempel. Ziegler-Natta catalysts for olefin polymerization: Mechanistic insights from metallocene systems. Progr. Polym. Sci. 20 (1995) 459-526.

${ }^{53}$ E.A. Moelwyn-Hughes. The Kinetics of Reaction in Solutions. Oxford University Press, London, 1947, p. 297.

${ }^{54}$ L. Qi, X. Qi, L. Wang, L. Feng, S. Lu. Decomposition of tert-butyl hydroperoxide into tert-butyl alcohol and 02 catalyzed by birnessite-type manganese oxides: Kinetics and activity. Catal. Comm. 49 (2014) 6-9.

${ }^{55}$ L. Matisová-Rychlá, J Richlý, I. Chodák, M. Lazár. Kinetic description of cumene hydroperoxide decomposition catalyzed by cobalt(II) naphthenate. Chemické Zvesti 31 (1977) 271-277.

${ }^{56}$ W.H. Richardson. Metal Ion Decomposition of Hydroperoxides. Kinetics and Products of Copper Salt Catalyzed Decomposition of t-Butyl Hydroperoxide IV. J. Am. Chem. Soc. 88 (1966) 975-979.

57 J. Bartoň, V. Horanská. Radical reactions initiated by chelate complexes of transition metals, 12. Decomposition of cumene hydroperoxide by the system copper acetate-aminoalcohol. Makromol. Chem. 175 (1974) 1861-1872.

${ }^{58}$ C. Methenitis, S. Skounas, G. Pneumatikakis, M. Morcellet. Kinetic Studies and Mechanism of Hydrogen Peroxide Catalytic Decomposition by $\mathrm{Cu}$ (II) Complexes with Polyelectrolytes Derived from L-Alanine and Glycylglycine. Bioinorg. Chem. Appl. 2010 (2010) Article number 643120.

59 I. Ben Talouba, L. Balland, N. Mouhab, M.A. Abdelghani-Idrissi. Kinetic parameter estimation for decomposition of organic peroxides by means of DSC measurements. J. Loss Prev. Proc. 24 (2011) 391-396.

${ }^{60}$ X.-R. Li, H. Koseki. Thermal decomposition kinetic of liquid organic peroxides J. Loss Prev. Proc. 18 (2005) 460464.

${ }^{61} \mathrm{~J}$. Bartoň, V. Horanská. Radical reactions initiated by chelate complexes of transition metals. VII. Effect of some copper chelates on the decomposition of cumene hydroperoxide in benzene. Makrom. Chem. 157 (1972) 87-101.

${ }^{62}$ L. Zikmund, J. Janota, J. Brodilová and J. Pospíšil. Antioxidants and stabilizers. XL. Contributors to the thermal decomposition of tert-butyl hydroxyperoxide. J. Polym. Sci. Polym. Symp. 40 (1973) 245-256.

${ }^{63}$ Z. Osawa, T. Shibamiya, T. Kawamata. Catalytic action of metallic salts in autoxidation and polymerization. IV. Polymerization of methyl methacrylate by cobalt(II) or (III) acetylacetonate-tert-butyl hydroperoxide or dioxane hydroperoxide. J. Polym. Sci. Pol. Chem. 8 (1970) 2957-2969.

${ }^{64}$ P.Y. Le Gac, D. Choqueuse, M. Paris, G. Recher, D. Melot. Durability of polydicyclopentadiene under high temperature, high pressure and seawater (offshore oil production conditions). Polym. Degrad. Stab. 98 (2013) 809-817. 